DOI: 10.14451/1.170.68

\title{
ПРЕДУПРЕЖДЕНИЕ БАНКРОТСТВА КАК ПРЕВЕНТИВНЫЙ ИНСТРУМЕНТ УПРАВЛЕНИЯ БАНКОВСКОЙ ДЕЯТЕЛЬНОСТЬЮ
}

\author{
(C) 2019 Анненков Алексей Юрьевич \\ кандидат юридических наук, доцент кафедры Государственного и административного права \\ Тульский государственный университет \\ 300012, г. Тула, пр. Ленина, 92 \\ E-mail: lex97531@mail.ru
}

(c) 2019 Бондаренко Татьяна Григорьевна

кандидат экономических наук, доцент кафедры финансового менеджмента

Российский экономический университет им. Г.В. Плеханова

115093, г. Москва, Стремянный пер., 36

E-mail: t.g.bondarenko@gmail.com

(c) 2019 Солтаханов Анзор Увайсович

кандидат экономических наук, доцент кафедры финансового менеджмента

Российский экономический университет им. Г.В. Плеханова

115093, г. Москва, Стремянный пер., 36

E-mail: ansolt13@gmail.com

В статье подняты вопросы определения банковского кризисного состояния, определены и классифицированы факторы, влияющие на возникновение кризисов в банке, развития банкротства коммерческого банка, проанализированы действия по предупреждению банкротства кредитных организаций за 2018 г., определен комплекс мер по предупреждению банкротства кредитной организации, представлены предлагаемые направления финансового оздоровления банка вне процедуры банкротства.

Ключевые слова: коммерческий банк, кредитная организация, банковский кризис, банкротство, несостоятельность, финансовое оздоровление.

Коммерческие банки [1] представляют собой часть кредитной системы РФ. Финансовая деятельность каждого банка напрямую влияет на финансовый сектор, банковский сектор, на состояние финансовой системы страны. Шаткое состояние одной кредитной организации (рисунок 1) может разрушить полностью всю систему финансовых институтов и экономики страны.

Как видно из данных рисунка 1 доля убыточных кредитных организаций практически не изменилась (29\% на начало анализируемо- го периола против 28\% на конец анлизируемого периода), именно поэтому необходимость в превентивном управлении деятельностью кредитных организаций, и как следствие - их антикризисном управлении - актуальна не только для стабильного развития банковской системы страны в целом, но и для каждой отдельной кредитной организации.

Кризисы в деятельности кредитных организаций бывают разных видов, определяемых в зависимости от причин их возникновения и
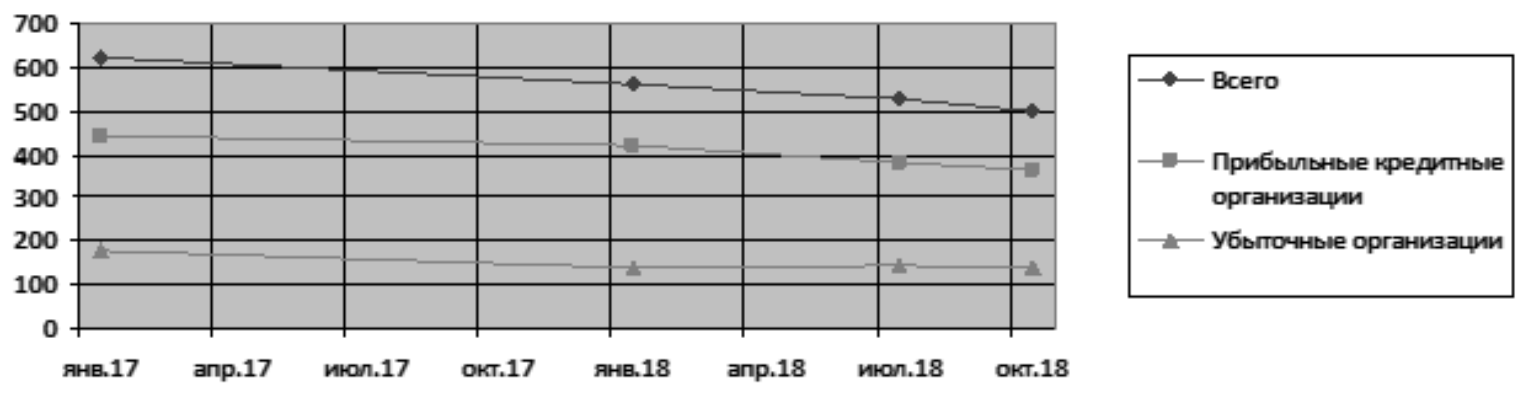

Puc. 1. Финансовый результат деятельности действующих кредитных организаций [2] 
других факторов. Представляется важным определить природу кризиса, чтобы в дальнейшем выбрать правильные превентивные методы для его преодоления и минимизации последствий. Кризисная ситуация в коммерческом банке всегда будет выражаться в экономических последствиях (недостаток денежных средств, увеличение затрат).

С одной стороны, банковский кризис - это неспособность большинства банков выполнять свои обязательства перед контрагентами - в первую очередь вкладчиками и кредиторами. С другой стороны, банковский кризис-крайнее обострение внутренних противоречий в банке (банковской системе), приводящее к угнетению его важнейших функций, угрожающее его стабильности и надежности [3].

K косвенным внешним негативным факторам, которые являются существенными для определения уровня кризисного состояния для коммерческих банков на современном этапе в РФ относят факторы, представленные на рисунке 2 [4].

K прямым внешним негативным факторам развития кризисной ситуации банков на современном этапе в РФ относят факторы, представленные на рисунке 3 [5].

Опасности, многократно усиленные де-

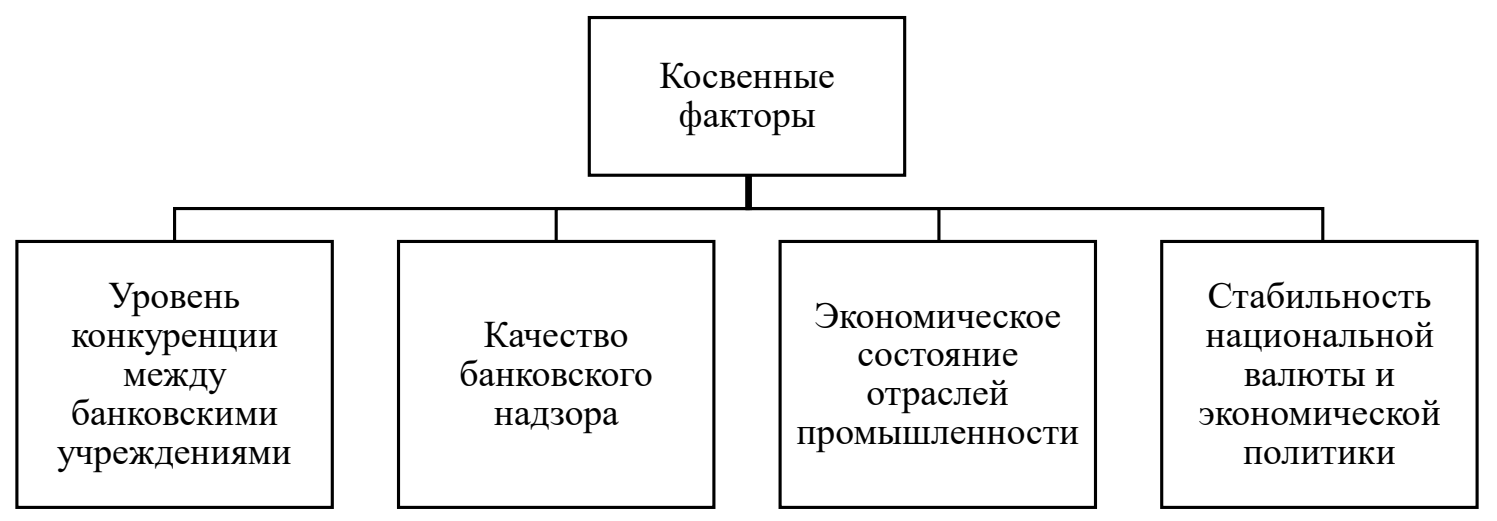

Pис. 2. Негативные косвенные факторы развития кризиса в банковской системе

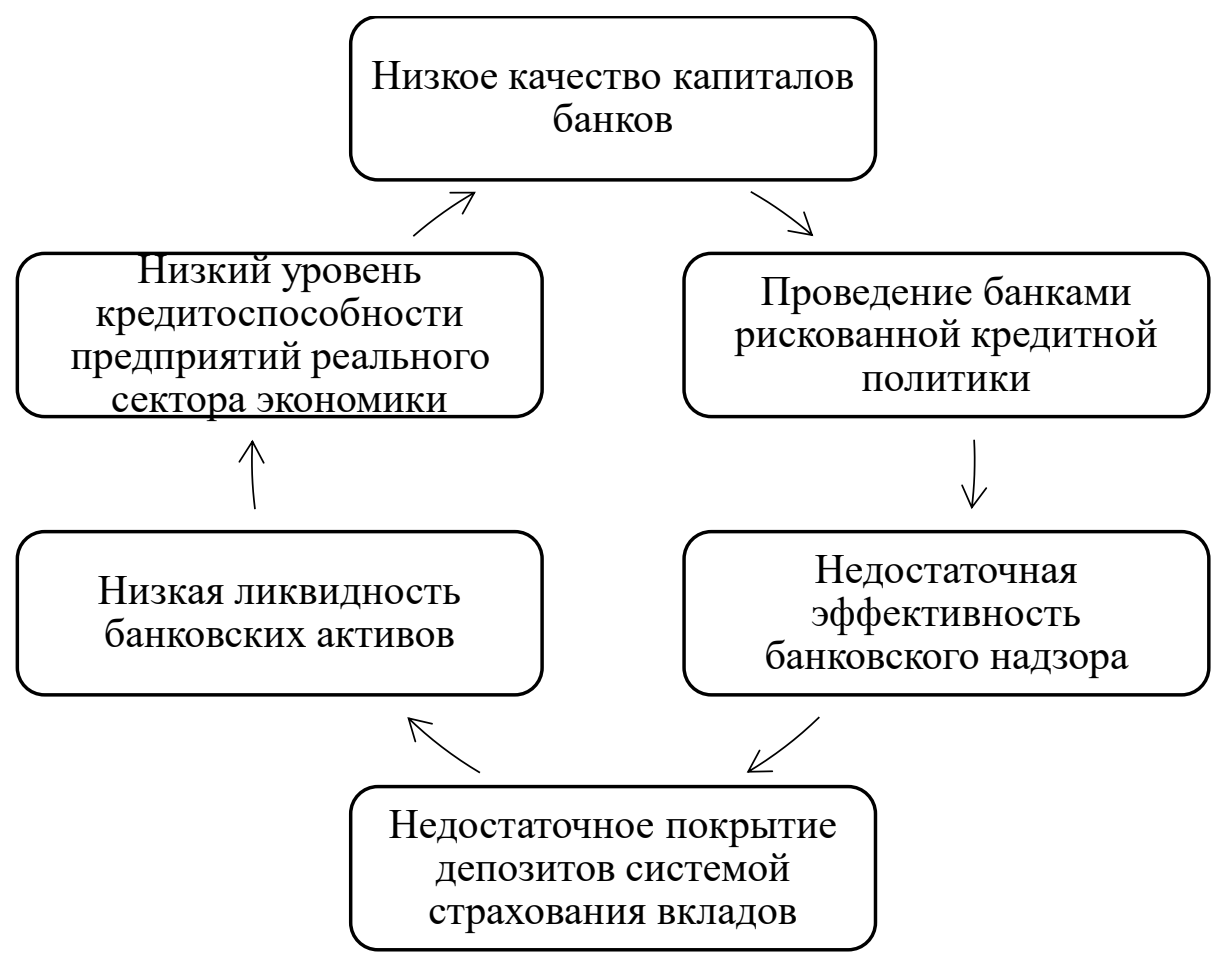

Рис. 3. Негативные внешние факторы развития кризиса банковской системы 
структивными факторами, оказывают мощное отрицательное воздействие, фактически представляя собой реализацию угрозы. Поскольку факторы способствуют отрицательному воздействию, они являются деструктивными. При этом внешние факторы воздействуют, как правило, на все банки в стране и являются масштабными. Внутренние деструктивные факторы действуют на конкретный коммерческий банк и являются менее масштабными, но не менее значимыми [4].

Формирование двухуровневой банковской системы [6] способствовало повышению устойчивости банковского сектора, но не предотвратило банковские кризисы. Так, с конца 1970-х гг. в разных регионах мира были зарегистрированы 117 эпизодов системных финансовых кризисов и 51 случай пограничных ситуаций и несистемных кризисов [7].

Превентивное управление (в частности в кредитной организации) - это одно из направлений менеджмента, как тактического, так и стратегического, которое включает в себя совокупность мероприятий, направленных на пред-

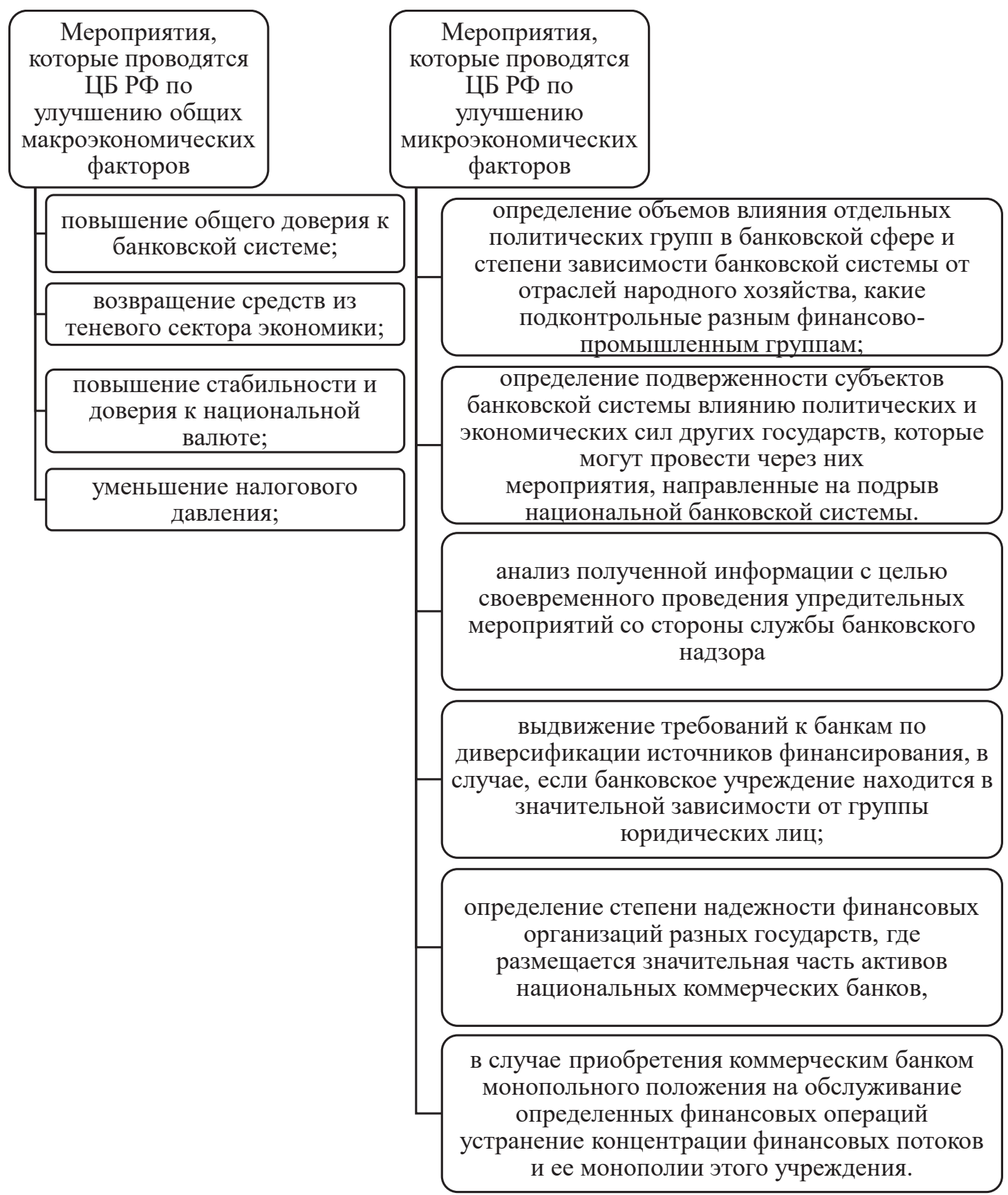

Рис. 4. Действия ЦБ РФ в целях повышения стабильности банковской системы 
видение кризиса в кредитной организации, недопущение или преодоление его, а также анализ полученных результатов для введения необходимых корректировок в деятельность кредитной организации.

Повышение эффективности как конечная цель предупреждения банкоротства банковской системы одновременно требует со стороны Банка России постоянного совершенствования качества надзора за банковскими учреждениями. Возможные действия Банка России в рамках реализации банковского надзора с целью повышения экономической стабильности коммерческих банков и последующего предупреждения риска развития банкротства на раннем этапе представлены на рисунке 4.

Из данных рисунка 4 видно, что повышение экономической стабильности банковской системы должно происходить через мероприятия, которые проводятся по улучшению общих макроэкономических факторов, так и по точечному воздействию на конкретные коммерческие банки или их группы.

Для характеристики кризисного состояния кредитной организации, используются такие термины, как несостоятельность, неплатёжеспособность и банкротство.
В законе [8] дается такое определение банкротства: «Банкротство (несостоятельность) признанная арбитражным судом неспособность должника в полном объеме удовлетворить требования кредиторов по денежным обязательствам, о выплате выходных пособий и (или) об оплате труда лиц, работающих или работавших по трудовому договору, и (или) исполнить обязанность по уплате обязательных платежей».

Согласно закону № 127-Ф3 «О несостоятельности (банкротстве)» меры по предупреждению банкротства банков могут осуществляться АСВ тремя путями (см. рисунок 5).

До объявления судом о банкротстве кредитной организации необходимо провести ряд судебных процедур и восполнить потребности кредиторов в полном размере. Поэтому, чтобы дать оценку кризисного состояния банка, необходимо использовать соответствующие количественные и качественные критерии. Помимо этого, необходимо дать оценку симптомам, причинам и факторам кризиса.

Отрицательные факторы обладают негативным влиянием на деятельность банка и реализуются в виде рисков. Риск представляет собой угрозу потери многочисленных источников, неполучение доходов, возникновение непредви-

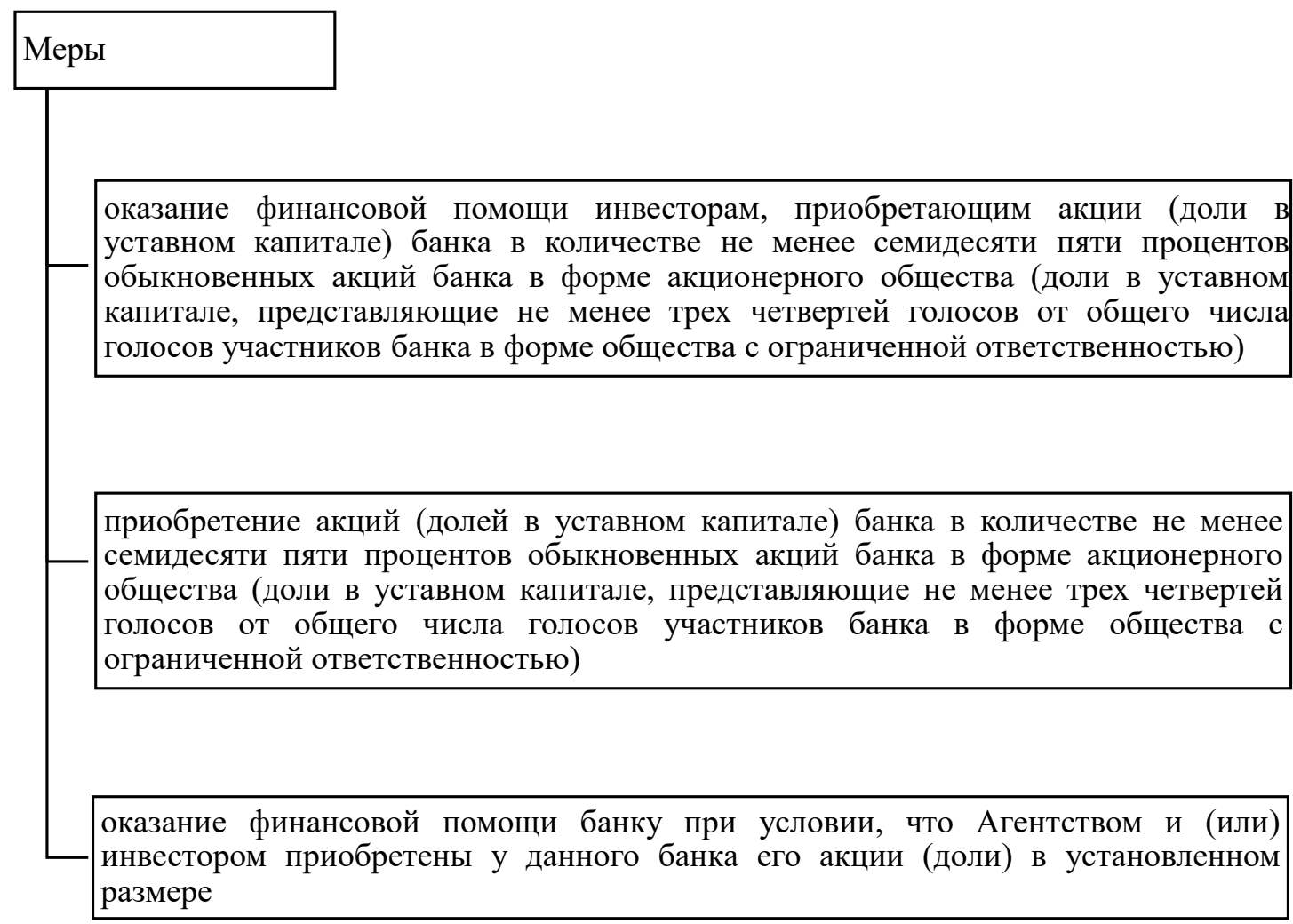

Рис. 5. Меры АВС по предупреждению банкротства банков 
денных расходов из-за финансовых операций. По этой причине первоначально антикризисное управление банком наступает с деятельности по разработке мер по регулированию возникающих банковских рисков.

Ниже на рисунке 6 выделены основные факторы, влияющие на возникновение кризисов в банке, на которые менеджмент кредитной организации должен обращать особое внимание и разрабатывать превентивные меры и антикризисные программы по снижению отрицательного действия данных факторов.

Рассмотрим влияние этих факторов с точки зрения реализации негативных тенденций, приведших к признакам банкротства кредитных организация и последующей ликвидации.

В 2017 году как Банком России, так и вре- менными администрациями по управлению кредитными организациями в адрес правоохранительных органов направлено 91 обращений с информацией о наличии в деятельности руководства и собственников кредитных организаций признаков уголовно наказуемых деяний, за первое полугодие 2018 г.- 45 подобных обращений, в том числе предусмотренных следующими статьями Уголовного кодекса Российской Федерации: ст. 159 «Мошенничество»; ст. 159.5 «Мошенничество в сфере страхования»; ст. 160 «Присвоение или растрата»; - ст. 195 «Неправомерные действия при банкротстве»; ст. 196 «Преднамеренное банкротство»; ст. 201 «Злоупотребление полномочиями» [9].

Действующее законодательство РФ предусматривает меры по предупреждению банкрот-

\section{Экономические}

Объём недостатка бюджета, объем долга, сокращение золотовалютных запасов страны, степень настоящих процентных ставок.

Степень инфляции, стабильность финансовой и экономических концепций.

Темпы увеличения ВВП, уровень диспропорциональности сфер экономики, требования предпринимательства, клиентов, снижение стоимости.

Кризисы иных государств.

Неопределенность рисков по финансовым инновациям.
Факторы

\section{Внутрибанковские}

Состав кредитного портфеля, степень просроченной ссудной задолженности, часть неликвидных активов на банковских балансах.

Уход от кредитования реальногосектора экономики в финансовый.

Развитие ресурсной базы банков за счет краткосрочных депозитов или внешних заемных средств.

Уровень квалификации менеджмента банка.

Степень капитализации банка.

\section{Правовые}

Нормативно-правовая база, регламентирующая полномочия, обязанности и ответственность банков, из контрагентов.

Практика регулировки работы кредитных учреждений: свободная концепция наблюдения.

\section{Социально-культурные}

Социально-цивилизационные характеристики социальных групп общества, характеризующие взгляды о степени и свойстве существования.

Непонимание и/или отрицание населением проводимой государством политики, предпринимательскими кругами, населением. 
ства кредитных организаций, представленные на рисунке 7.

К данным мерам можно прибегнуть только в определенных случаях, указаных в законодательстве. Например, когда кредитная организация более полугода неоднократно не удовлетворяет требования кредиторов по денежным обязательствам в связи с отсутствием денежных средств на его корреспондентских счетах.

Хотя страны мира отличаются своими финансовыми и правовыми системами, регулирование и надзор за деятельностью банков отличен в силу исторического развития страны, менталитета, уровня экономики, разница в количестве кредитных организаций и их размеров. Но существует общий набор инструментов, который эффективен в каждом из перечисленных ранее состояний банковской системы.

Системный банковский кризис невозможно устранить с помощью локальных антикризисных мер. Так как данный кризис является глубоким, поскольку затронул всю систему банков в стране. Снятие напряженности будет малоэффективным, хотя будут ликвидированы нежизнеспособные компании, но масштабы кризиса требуют применения емких разносторонних решений, охватывающих всю банковскую систему страны. В данном случае потребуется реструктуризация национальной банковской системы.

При кризисах отдельных финансовых единиц необходимы такие превентивные антикризисные мероприятия, которые позволят на ранней стадии выявить и минизировать риски развития банкротства, а в широком смысле - не позволят выйти кризису за рамки данного банка и стать системным.

С целью эффективного выполнения программ антикризисного управления и составле- ния мероприятий по превентивному контролю развития признаков банкротства кредитной организации применяются консультационно-умозаключительные способы, с поддержкой которых исследуется и предоставляется анализ финансового состояния банка (кредитной организации). Задача подобного исследования заключается в раскрытии трудностей и концепции управления рисками, исследованию функционирования организационной и финансовой структуры кредитной организации. Превентивные меры по снижению риска развития кризисных событий в банке и его последующему банкротству способны стать эффективным способом управления деятельностью кредитных организаций.

Необходимо отметить, что в РФ на практике коммерческие банки вынуждены каждый раз в зависимости от характера кризиса и его масштаба разрабатывать принципиально новые антикризисные меры и программы, чтобы не допустить своего банкротства.

Превентивные меры по развитию признаков банкротства кредитных организаций заключаются в разработке механизмов и выбору инструментов, использование которых за счет сильных внутренних сторон окажет воздействие на сокращение угроз внешней среды. Например, возникновение новых конкурентов на рынке банковских услуг можно избежать за счет поддержания высокого уровня качества оказываемых услуг, обширного перечня банковских услуг и продуктов, чуткого отношения к клиентам, гибкой системы скидок, повышения финансового контроля и качества управленческого процесса и развития кадровой политики, что в совокупности сделает бизнес успешно управляемым и создаст мощный потенциал для конкурентной борьбы.

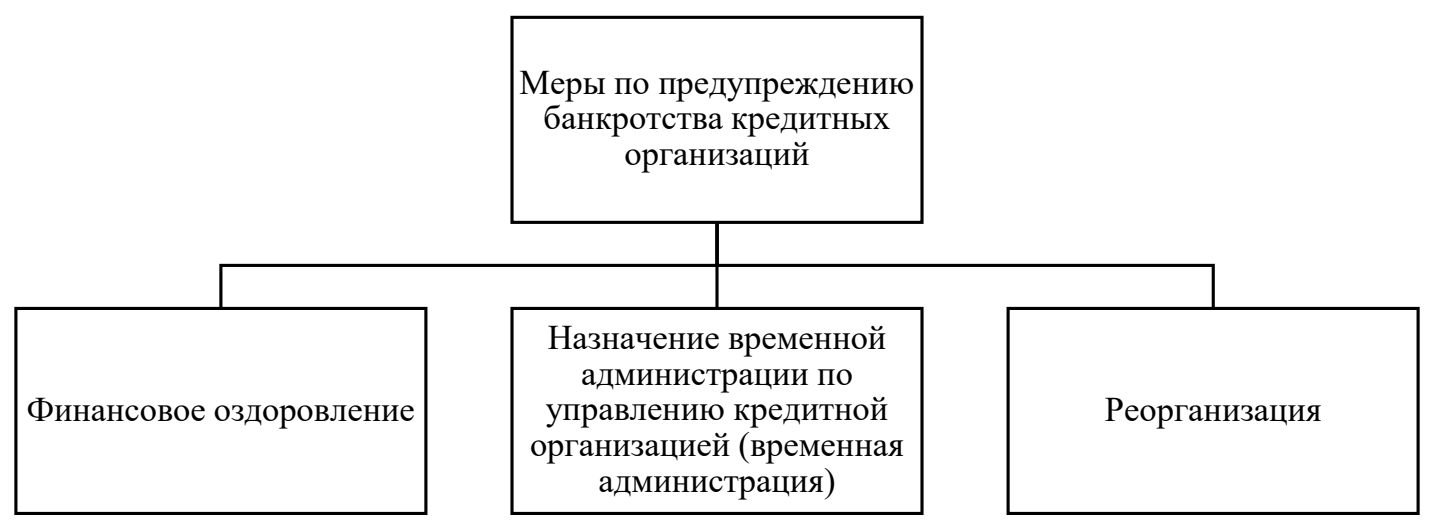

Puc. 7. Меры по предупреждению банкротства в рамках действующего законодательства 


\section{Библиографический список}

1. Федеральный закон от 02.12.1990 № 395-1 «О банках и банковской деятельности» (ред. от 27.12.2018)

2. Обзор банковского сектора Российской Федерации (интернет-версия). Аналитические показатели. № 1942018 год. // Официальный сайт Центрального банка Российской Федерации (Банка Poccии) URL: http://www.cbr.ru/Collection/Collection/File/10406/obs_194.pdf

3. Ткаченко Р.В. Стресс-тестирование в коммерческом банке: обзор и анализ методологии//Экономика и предпринимательство. 2014. № 1-2(42-2). С. 520-522.

4. Наточеева Н.Н. Стратегическая финансовая безопасность коммерческих банков: монография. Москва. 2011. 117 c.

5. Х Хасянова С.Ю. Кредитный анализ в коммерческом банке: учебное пособие. Москва. 2016.197 с.

6. Федеральный закон от 10 июля 2002 г. № 86-Ф3 «О Центральном банке Российской Федерации (Банке России)» (с изм. и доп. от 3 августа 2018 г.)

7. Хоггарт Г. Разрешение банковских кризисов: основные инструменты и издержки [Текст] / Г.Хоггарт, Дж. Рейдхилл, П. Синклер // Банки: мировой опыт. 2011. № 34. С.108-109.

8. Федеральный закон от 26.10.2002 № 127-ФЗ «О несостоятельности (банкротстве)» (с изм. и доп. от 12 ноября 2018 г.)

9. Прекращение деятельности кредитных организаций. Первое полугодие 2018 г. // Официальный сайт Центрального банка Российской Федерации (Банка России) URL: http://www.cbr.ru/Content/Document/ File/47595/pub_1h18.pdf [Электронный ресурс]. Дата обращения 01.12.2018

Поступила в редакцию 18.01.2019 